\title{
In memoriam Dr. Joseph Kayle Perloff
}

\author{
Harald Kaemmerer • Peter Ewert • John Hess • \\ Hans-Carlo Kallfelz
}

Published online: 25 September 2014

(C) Springer-Verlag Berlin Heidelberg 2014

Dr. Joseph Kayle Perloff, founder of the new specialty of Cardiology_"Adults with congenital heart disease"-has passed away on the morning of August 18, 2014, at the age of 89 years at his home in Pacific Palisades, Los Angeles (Fig. 1).

J. K. Perloff was born on 21 December 1924 in New Orleans.

He graduated from Tulane University 1945 and completed his medical studies in 1951 at Louisiana State University.

His medical training took him to the Mount Sinai Hospital in New York, and then, as a Fulbright Fellow, to Dr. Paul Hamilton Wood, Institute of Cardiology in London.

Returning to the USA he worked at the National Institutes of Health (NIH) and at Georgetown University, Washington, where he soon received his first professorship. Subsequently, he was "Chief of the Section of Cardiology" at the University of Pennsylvania in Philadelphia.

As a "Streisand/American Heart Association Professor of medicine and pediatrics" he moved in 1977 to the UCLA in Los Angeles, where he built up one of the world's most renowned facilities for the care of adults with congenital heart defects.

He was one of the first ever, who realized that the specific care of adults with congenital heart disease was urgently needed because children with congenital heart defects reached adulthood in increasing numbers, and only

H. Kaemmerer $(\bowtie) \cdot$ P. Ewert · J. Hess

Deutsches Herzzentrum München, Klinik an der Technischen Universität München, Lazarettstr. 36, 80636 Munich, Germany e-mail:Kaemmerer@dhm.mhn.de

\section{H.-C. Kallfelz}

Klinik für Pädiatrische Kardiologie, Medizinische Hochschule Hannover, Carl-Neuberg-Str. 1, 30625 Hannover, Germany a few cardiologists were willing and able, to provide adequate care for these new and complex patients.

Consequently, he developed this new field of cardiology at UCLA and within the following years this institution became a place of pilgrimage for cardiologists from all around the world who were following him and his example and tried to establish similar centers in their cities or countries.

In 2001 he became Professor Emeritus of UCLA, but continued to work clinically and scientifically in his field.

J. K. Perloff has received many national and international awards and honors for his clinical and scientific achievements.

His personal commitment and the intense devotion to HIS patients were incomparable.

In addition to hundreds of medical publications J. K. Perloff wrote the well known textbooks "Clinical

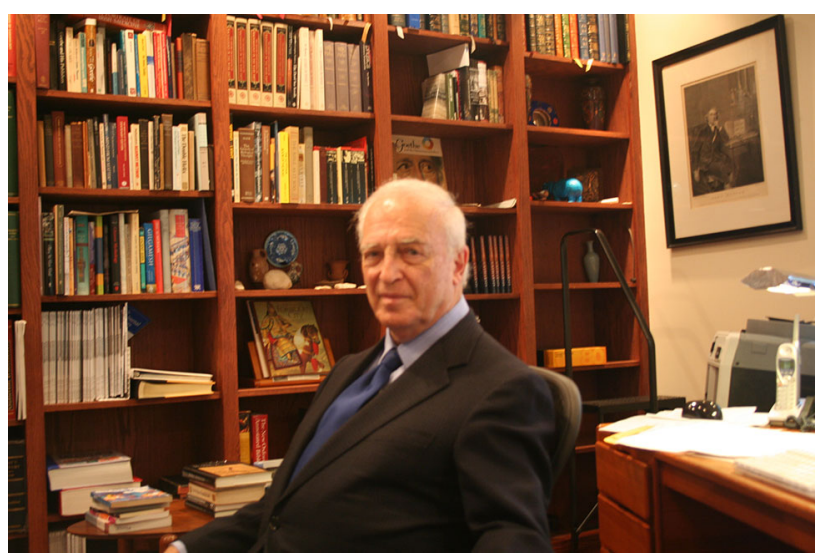

Fig. 1 Dr. Joseph Kayle Perloff, founder of the new specialty of Cardiology_"Adults with congenital heart disease" (Courtesy: Marjorie Perloff, Los Angeles, USA) 
Recognition of Congenital Heart Disease", "Congenital Heart Disease in Adults" and "Physical Examination of the Heart and Circulation", all published in several editions.

He is survived by his wife Marjorie Perloff, professor, literary critic and humanist in Stanford and USC, and his daughters Nancy and Carey and their three children.
We have lost an impressive personality, a great physician and a steady promoter of science and teaching. His patients owe him much and will always remember him. As an exceptionally gifted academic teacher his students and disciples will never forget him and they will all remember Joseph K. Perloff in respect and gratitude. 